\title{
Dynamic Characteristics of Pulse Rate Control of a POL Converter
}

\author{
Ichiro Nishikawa*, Masao Ueno*,**,Yoichi Ishizuka*, Hirofumi Matsuo* and Jyoichi Saito** \\ *Nagasaki University, Nagasaki, Japan \\ **Sanken Electric Co., Ltd., Saitama, Japan
}

\begin{abstract}
From the perspective of good point-of-load (POL) designs, a fast response for load-change and high power efficiency are important factors. Pulse width modulation (PWM) control is a common control method for POL. Although this control method is very simple and stable for POL, the response for sudden load change is not so fast because of its fixed frequency. However, pulse rate control (PRC) is well suited to such applications. The PRC control method and its features are described, and advantages of PRC are revealed with the some simulated and experimental results.
\end{abstract}

\section{INTRODUCTION}

Recently, power management has been introduced to improve the power efficiency of Micro Processing Unit (MPUs), Field Programmable Gate Array (FPGAs) and Digital Signal Processor (DSPs). The power management system includes a full operation mode, standby, and sleep modes. The clock frequency, core voltage and/or core current are changed in each mode accordingly. As a result, the output current of the point-of-load (POL) DC-DC converters is intermittent and has a high slew rate.

A low output voltage, a large output current and a highspeed response, are required for the POL [1].

In such a condition for the control circuit, highly accurate and high-speed control demands that the tolerance of the output voltage becomes internally severe, advanced by speed-up and lowering of the voltage of the MPUs, FPGAs and DSPs $[2,3]$. A general control method is pulse width modulation (PWM) control. However, for PWM control, the switching frequency is fixed and in this case a delay in the frequency band region results where the change of the load is higher than the switching frequency, especially a delay in the response is caused. In the worst case, the control does not catch up and there exists a possibility that the MPUs, FPGAs and DSPs will stop. In addition, there is a problem in that the ripple of the reactor current increases after the load current increases, as given by the DC bias current characteristics.

This study reveals the problem of PWM control of a POL converter, and proposes the use of pulse rate control (PRC).

PRC consists of a monostable multivibrator and an analog comparator. Switching can be immediately turned on for a change in the load, and a fast-speed response can be achieved. The change of the switching frequency causes suppression of an increase in the ripple of the reactor current.
Firstly, the basic circuitry and problems of PWM control are explained. Then a basic circuitry and the basic principle of operation regarding the PRC method are explained. In addition, the relation between the DC bias current characteristics, the ripple of the reactor current, and the effectiveness of the dynamic characteristic of the PRC method are revealed.

The results of a computer simulation are given regarding the response to a change of output voltage and ripple of the reactor current using circuit simulator Ansoft Simplorer. The experimental results are similarly shown.

\section{PWM CONTROL}

Fig. 1 shows PWM control of a POL converter, where $\mathrm{L}$ is the choke inductor and $\mathrm{C}_{\mathrm{CO}}$ is the output capacitor. $\mathrm{R}_{\mathrm{CO}}$ and $\mathrm{L}_{\mathrm{CO}}$ are the equivalent series resistance and the reactor of $\mathrm{C}_{\mathrm{O}}$, respectively. In basic operation, the gate-pulse of $\mathrm{SW}_{1}$ and $\mathrm{SW}_{2}$ is output from a comparator with inputs of a triangular waveform and $\mathrm{V}_{\text {err. }}$. $\mathrm{V}_{\text {err }}$ is determined from the output voltage $\mathrm{e}_{\mathrm{o}}$, and a target voltage $\mathrm{V}_{\text {ref }}$, through differential amplification with phase compensation.

Fig. 2 shows waveforms at load-change from light load to heavy load. The delay in the response is caused because the switching frequency is fixed for the PWM control method. To achieve a high-speed response for large load changes, speeding-up of the switching speed and addition of phases for multi-phasing are the general methods [4]. However, large switching losses and circuit size become problematic.

The output voltage $e_{o}$, is calculated as

$$
e_{o}=\frac{T_{\text {on }}}{T_{\text {on }}+T_{\text {off }}} E_{i}
$$

where $E_{i}$ is the input voltage, and $T_{\text {on }}$ and $T_{\text {off }}$ are on and off terms.

The delay time $t_{d}$, shown in Fig. 2 , is determined by

$$
\frac{(1-D)}{2 f_{s}}<t_{d}<\frac{(1-D)}{f_{s}}
$$

where $D$ is the duty ratio and $f_{s}$ is the switching frequency. From Eq. (2), it is apparent that $t_{d}$ always exists in PWM control. 


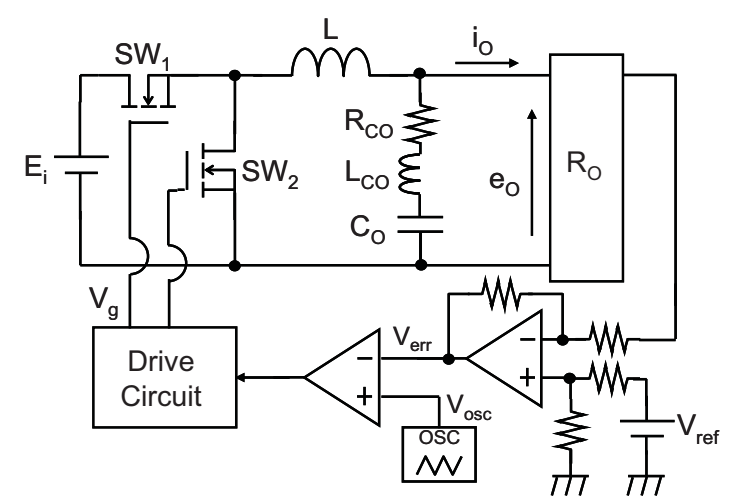

Fig. 1. PWM-controlled POL converter

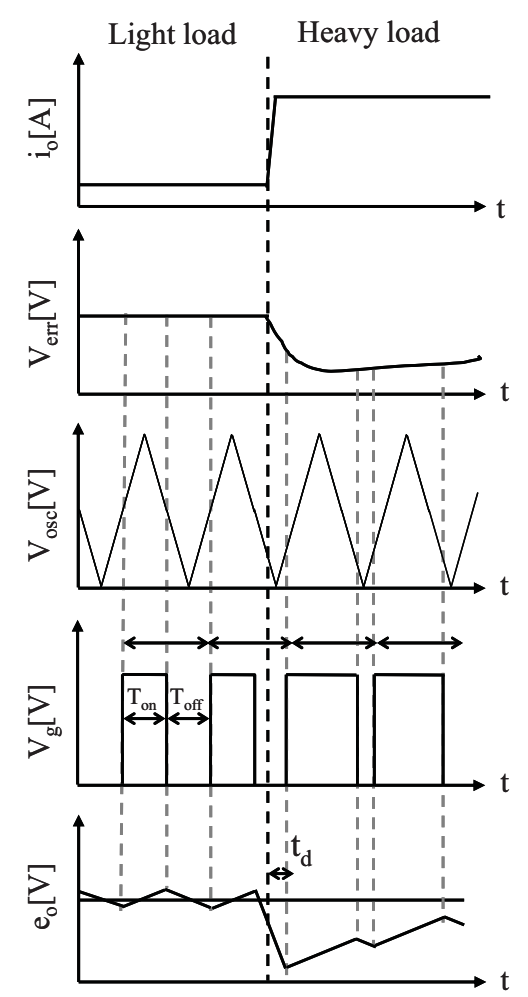

Fig. 2. Load-change from light load to heavy load.

\section{Proposed Control CirCuIT}

\section{A. Basic Operation}

Fig. 3 shows the proposed PRC control circuit for the POL converter, where $\mathrm{L}$ is the choke inductor and $\mathrm{C}_{\mathrm{O}}$ is the output capacitor. $\mathrm{R}_{\mathrm{CO}}$ and $\mathrm{L}_{\mathrm{CO}}$ are equivalent series resistance and reactor of $\mathrm{C}_{\mathrm{O}}$, respectively. The control block is basically composed of a comparator and a monostable multivibrator. $\mathrm{V}_{\text {ref }}$ is set slightly below a target output voltage $\mathrm{E}_{\mathrm{o}}$.

The comparator outputs a high-level signal just after the $e_{o}$ dips from $V_{\text {ref. }}$ The monostable multivibrator then outputs a pulse signal after receiving the high-level signal. The highlevel signal of the monostable multivibrator continues to preset the term as a fixed on-term of the high-side switch $\mathrm{SW}_{1}$. The term between the end of the on-term and the start of the next high-level output of the comparator is the off-term of the high-side switch $\mathrm{SW}_{1}$. Therefore, this control method can respond to load changes faster than a PWM response, especially a change from a light load to a heavy load.

$\mathrm{T}_{\text {on }}$ for PRC is constant, and $\mathrm{T}_{\text {off }}$ is determined as

$$
T_{o f f}=\frac{2 L \cdot \Delta e_{o}}{\left(\Delta e_{o}+2 V_{r e f}\right) \cdot R_{c o}}
$$

where $\Delta \mathrm{e}_{\mathrm{o}}$ is the ripple voltage of $\mathrm{e}_{\mathrm{o}}$.

From Eqs. (1) and (3), the following is derived

$$
e_{o}=\frac{T_{o n}}{T_{o n}+\frac{2 L \cdot \Delta e_{o}}{\left(\Delta e_{o}+2 V_{r e f}\right) \cdot R_{c o}}} E_{i} .
$$

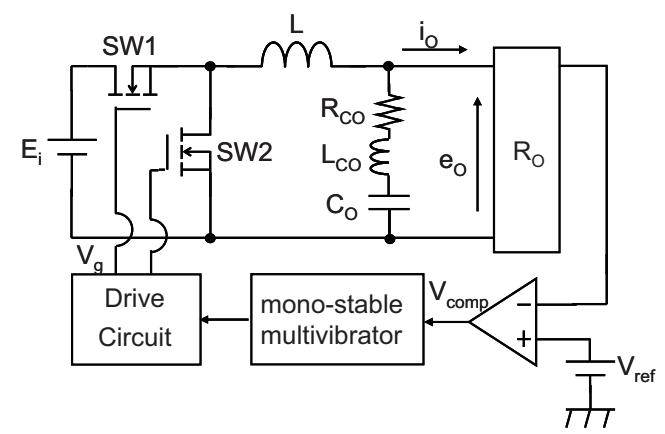

Fig. 3. Proposed PRC POL converter

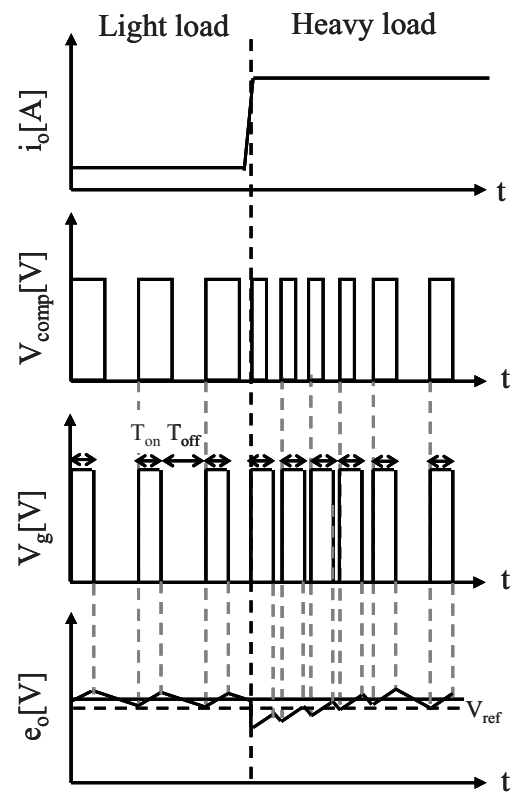

Fig. 4. Load-change from light load to heavy load 


\section{B. Suppression of the Ripple of Reactor Current}

The requirements for a good choke-coil of a power supply circuit are low core-loss, miniaturization, and excellent DC bias current characteristics, etc.

However, these requirements become mutual trade-offs. Miniaturization deteriorates the DC bias current characteristics. This is especially a serious problem for control when the load-change is large, as shown in Fig. 4.

The DC bias current characteristics of a ferrite core are more excellent than those of a dust core. In any case, the inductance changes if the range of the change of direct current broadens.

The ripple of the reactor current $\Delta \mathrm{i}_{\mathrm{L}}$, is defined as

$$
\Delta i_{L}=\frac{E_{o} \cdot\left(E_{i}-E_{o}\right)}{L \cdot f_{s} \cdot E_{i}} E_{i}
$$

From Eq. (5), the value of $E_{i}, E_{o}$ and $f_{s}$ are constant for PWM control. When the load current increases, the inductance $\mathrm{L}$ is decreased by the DC bias current characteristic shown in Fig. 5. As a result, the ripple of the reactor current is increased.

On the other hand, the switching frequency is not fixed in the PRC method. When the load current increases, the switching frequency increases, too. This is evident from the relation between $\mathrm{I}_{\mathrm{o}}$ and $\mathrm{f}_{\mathrm{s}}$.

$$
f_{s}=\left(1+\frac{R_{c o} I_{o}}{E_{o}}\right) \cdot \frac{E_{o}}{E_{i}} \cdot \frac{1}{T_{o n}} .
$$

Fig. 6 shows the $\mathrm{I}_{\mathrm{o}}-\mathrm{f}_{\mathrm{s}}$ characteristics under the conditions of $\mathrm{T}_{\text {on }}=0.5 \mu \mathrm{s}, \mathrm{E}_{\mathrm{o}}=1.5 \mathrm{~V}, \mathrm{R}_{\mathrm{CO}}=0.05 \Omega$.

Therefore, even if a large load change occurs from a light load to a heavy load, an increase of ripple can be decreased by the switching frequency increase, more than that by PWM control.

As a result, PRC control can improve the problem of DC bias current characteristics. It is also proposed that a low-cost dust core can be adopted as a reactor.

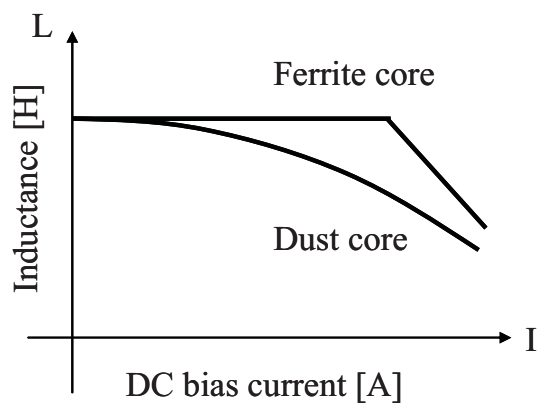

Fig. 5. DC bias current characteristics

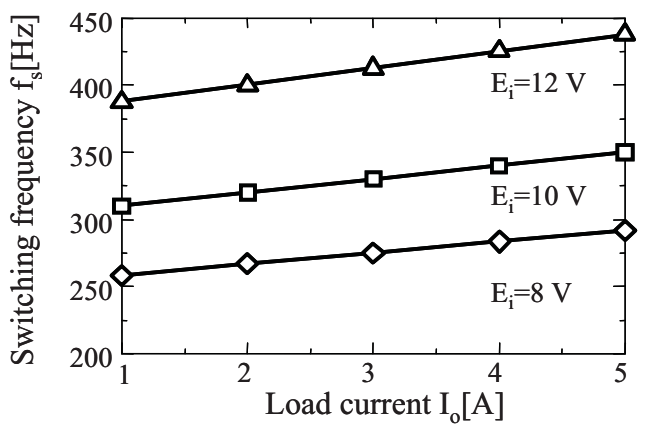

Fig. 6. $\mathrm{I}_{\mathrm{o}}-\mathrm{f}_{\mathrm{s}}$ characteristics

\section{Simulation RESUlTS}

The computer simulation analysis for PWM and PRC control were performed with a circuit simulator Ansoft Simplorer.

Table 1 and 2 give the parameters and conditions used.

\section{A. PWM Control}

Fig. 7 shows waveforms for $\mathrm{e}_{\mathrm{o}}, \mathrm{i}_{\mathrm{L}}$ and $\mathrm{v}_{\mathrm{g}}$ at the change point from light load to heavy load.

From the results of PWM control, a response time of 170 $\mu$ s was confirmed, with an undershoot of $69 \mathrm{mV}$ and an overshoot of $25 \mathrm{mV}$. The percentage of the output voltage ripple is $1.56 \%$. The ripple of the reactor current is $0.98 \mathrm{~A}$ at light load, and $1.02 \mathrm{~A}$ at heavy load. Therefore, the ripple of the reactor current increases by approximately $40 \mathrm{~mA}$. The switching frequency is fixed at $500 \mathrm{kHz}$, and the on-term increases to step up the output voltage in the load change.

Fig. 8 shows waveforms for $\mathrm{e}_{\mathrm{o}}, \mathrm{i}_{\mathrm{L}}$ and $\mathrm{v}_{\mathrm{g}}$ at the change point from heavy load to light load.

From the results of PWM control, a response time of $150 \mu \mathrm{s}$ was confirmed, with an undershoot of $25 \mathrm{mV}$, and an overshoot of $70 \mathrm{mV}$. The switching frequency is fixed at $500 \mathrm{kHz}$, and the on-term decreases to step down the output voltage in the load change

Table I.

PARAMETERS AND CONDITIONS For THE SimUlation.

\begin{tabular}{|c||c|} 
PARAMETERS AND CONDITIONS FOR THE SIMULATION. \\
\begin{tabular}{|c||c|}
\hline Input voltage $\mathrm{E}_{\mathrm{i}}$ & $12 \mathrm{~V}$ \\
\hline Output voltage $\mathrm{e}_{\mathrm{o}}$ & $1.5 \mathrm{~V}$ \\
\hline Switching frequency fs & $500 \mathrm{kHz}$ \\
\hline Choke inductor $\mathrm{L}$ & $2.7 \mu \mathrm{F}$ \\
\hline Output capacitor $\mathrm{C}_{\mathrm{o}}$ & $400 \mu \mathrm{F}$ \\
\hline Equivalent series resistance $\mathrm{R}_{\mathrm{CO}}$ & $20 \mathrm{~m} \Omega$ \\
\hline Equivalent series reactor $\mathrm{L}_{\mathrm{CO}}$ & $1 \mathrm{nH}$ \\
\hline Load current $\mathrm{i}_{\mathrm{o}}$ (light load-heavy load) & $1 \mathrm{~A}-3 \mathrm{~A}$ \\
\hline Load change slew-rate $(\mathrm{SR})$ & $50 \mathrm{~A} / \mu \mathrm{s}$ \\
\hline
\end{tabular}
\end{tabular}

Table II.

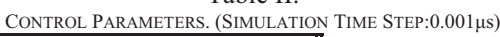

\begin{tabular}{|c||c|}
\hline PWM control method & \\
\hline \hline Proportional gain $\mathrm{H}_{\mathrm{P}}$ & 10 \\
\hline Integral gain $\mathrm{H}_{\mathrm{I}}$ & 150000 \\
\hline PRC method & \\
\hline \hline On-term $\mathrm{T}_{\mathrm{ON}}$ & $0.25 \mu \mathrm{s}$ \\
\hline Minimum Off-term $\mathrm{T}_{\text {OFF }}$ & $0.75 \mu \mathrm{s}$ \\
\hline $\mathrm{V}_{\text {ref }}$ & $1.49 \mathrm{~V}$ \\
\hline
\end{tabular}




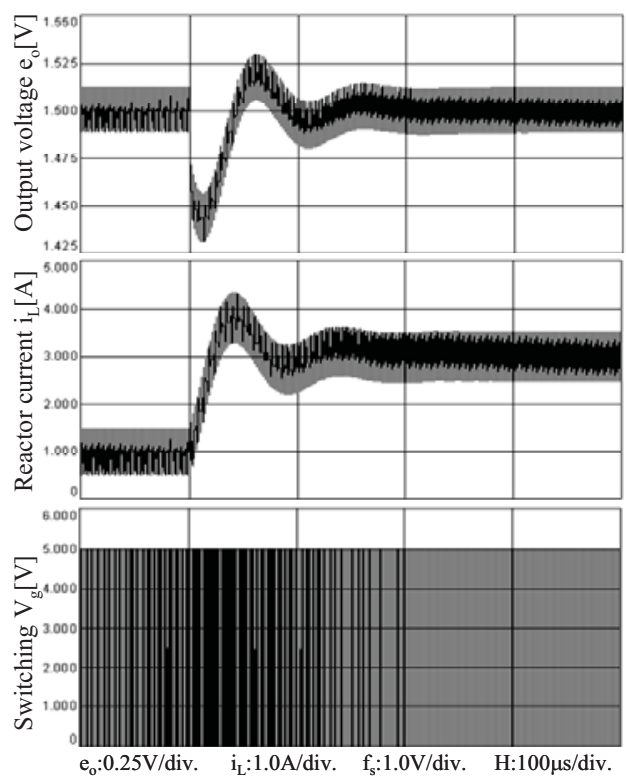

Fig. 7. Load-change simulation results from light load to heavy load (PWM control).

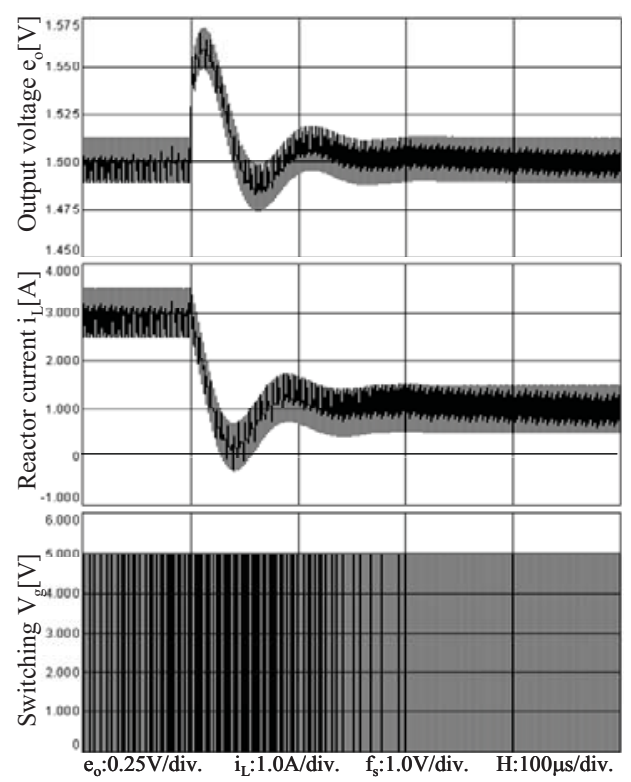

Fig. 8. Load-change simulation results from heavy load to light load (PWM control).

\section{B. Proposed PRC Control}

Fig. 9 shows waveforms for $\mathrm{e}_{\mathrm{o}}, \mathrm{i}_{\mathrm{L}}$ and $\mathrm{v}_{\mathrm{g}}$ at the change point from light load to heavy load.

From the results of PRC, a response time of $4 \mu \mathrm{s}$ was confirmed, with an undershoot of $35 \mathrm{mV}$. The percentage of the output voltage ripple is $1.53 \%$. The ripple of the reactor current is $0.982 \mathrm{~A}$ at light load, and $0.965 \mathrm{~A}$ at heavy load. Therefore, the ripple of the reactor current decreases by approximately $17 \mathrm{~mA}$. The switching frequency is 500,530 $\mathrm{kHz}$ and $1 \mathrm{MHz}$ at light load, during transition, and at heavy load, respectively. When the load current increases, it was confirmed that the switching frequency also increases.

Fig. 10 shows waveforms for $\mathrm{e}_{\mathrm{o}}, \mathrm{i}_{\mathrm{L}}$ and $\mathrm{v}_{\mathrm{g}}$ at the change point from heavy load to light load. From the results of PRC, the response time was confirmed as $5 \mu \mathrm{s}$, with an overshoot is $35 \mathrm{mV}$. The switching waveform was kept off-term during transition, until the output voltage decreased to the target output voltage.

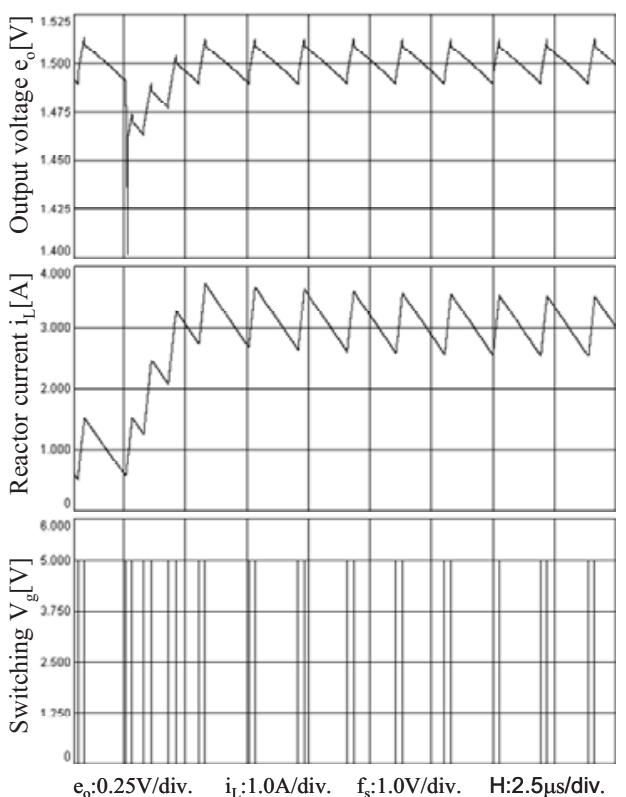

Fig. 9. Load-change simulation results from light load to heavy load (PRC).

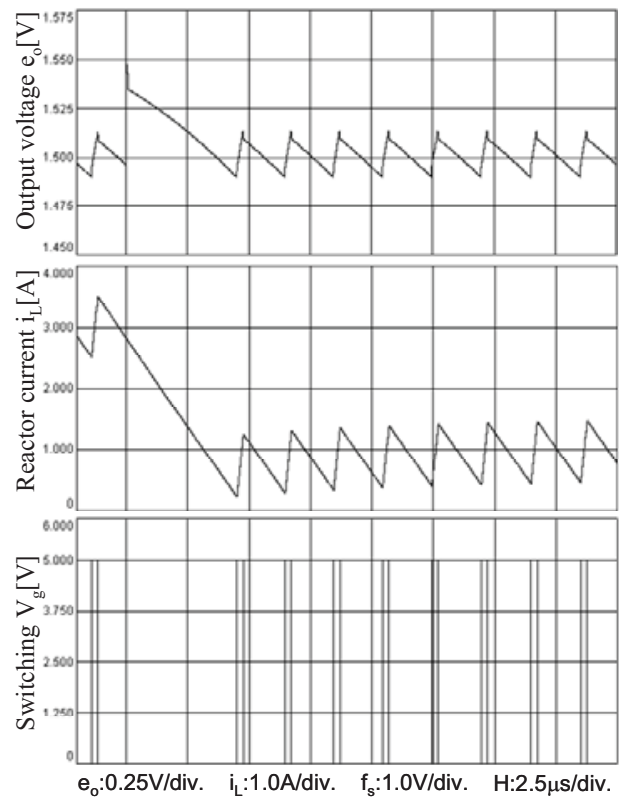

Fig. 10. Load-change simulation results from heavy load to light load (PRC). 


\section{EXPERIMENTAL RESULTS}

\section{A. PWM Control}

The experiments were performed using a PWM control-IC (TPS40050, Texas Instruments Co.) [5].

Fig. 11 shows the experimental circuit, and Table 3 gives the experimental conditions.

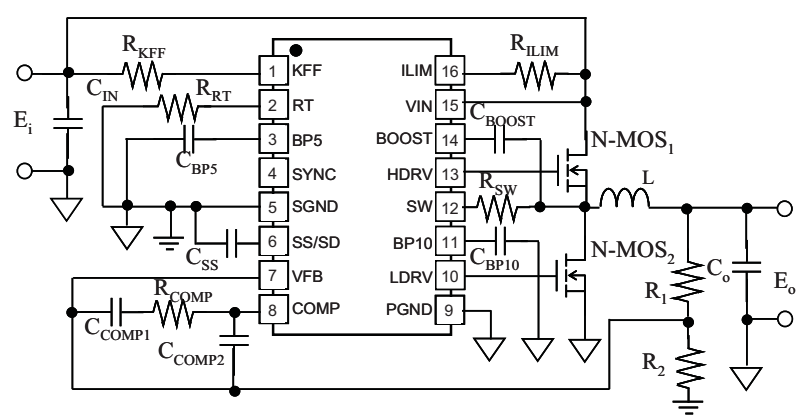

Fig. 11. Experimental circuit (PWM).

Table III.

EXPERIMENTAL CoNDITIONS.
\begin{tabular}{|c|c|c||c|}
\hline Input voltage $\mathrm{E}_{\mathrm{i}}$ & $8 \mathrm{~V}$ & $\begin{array}{c}\text { Load current } \mathrm{i}_{\mathrm{o}} \\
\text { (light load-heavy load) }\end{array}$ & \multirow{2}{*}{$0.6 \mathrm{~A}-1.4 \mathrm{~A}$} \\
\hline Output voltage $\mathrm{E}_{\mathrm{o}}$ & $4 \mathrm{~V}$ & & \\
\cline { 1 - 2 } Switching frequency $\mathrm{f}$ & $500 \mathrm{kHz}$ & Choke inductor L & $2.7 \mu \mathrm{F}$ \\
\hline $\mathrm{C}_{\mathrm{BOOST}}$ & $0.1 \mu \mathrm{F}$ & Output capacitor $\mathrm{C}_{\mathrm{o}}$ & $330 \mu \mathrm{F}$ \\
\hline $\mathrm{R}_{\mathrm{KFF}}$ & $30 \mathrm{k} \Omega$ & Input capacitor $\mathrm{C}_{\text {in }}$ & $20 \mu \mathrm{F}$ \\
\hline $\mathrm{R}_{\mathrm{SW}}$ & $3.3 \mathrm{k} \Omega$ & $\mathrm{R}_{1}$ & $100 \mathrm{k} \Omega$ \\
\hline $\mathrm{R}_{\mathrm{RT}}$ & $90 \mathrm{k} \Omega$ & $\mathrm{R}_{2}$ & $13.2 \mathrm{k} \Omega$ \\
\hline $\mathrm{R}_{\mathrm{LIM}}$ & $3.09 \mathrm{k} \Omega$ & $\mathrm{C}_{\mathrm{BP} 10}$ & $1 \mu \mathrm{F}$ \\
\hline $\mathrm{C}_{\mathrm{BP} 5}$ & $0.1 \mu \mathrm{F}$ & $\mathrm{C}_{\mathrm{SS}}$ & $3300 \mathrm{pF}$ \\
\hline $\mathrm{C}_{\mathrm{COMP} 1}$ & $1000 \mathrm{pF}$ & $\mathrm{C}_{\mathrm{COMP} 2}$ & $82 \mathrm{pF}$ \\
\hline
\end{tabular}

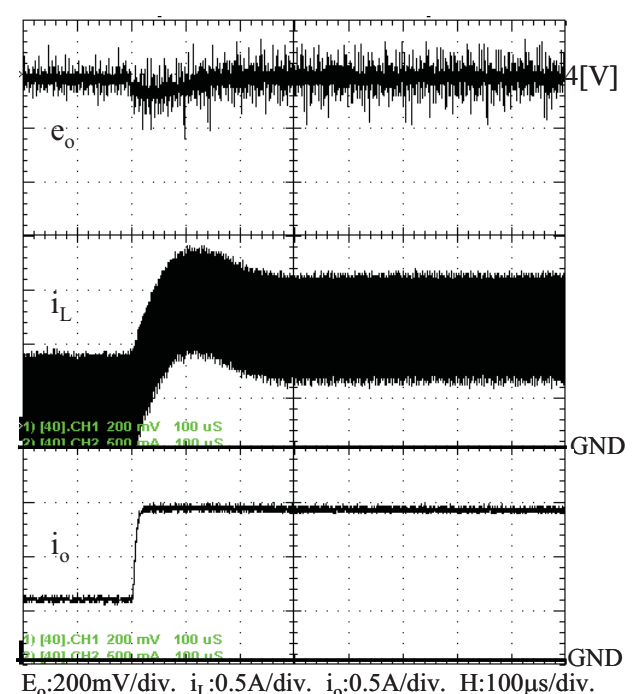

Fig 12. Load-change experimental results from light load to heavy load (PWM control).

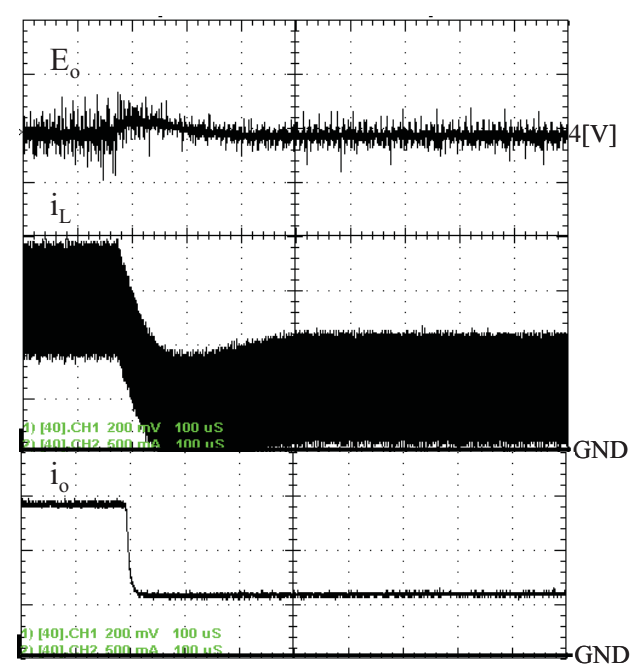

$\mathrm{E}_{\mathrm{o}}: 200 \mathrm{mV} /$ div. $\mathrm{i}_{\mathrm{L}}: 0.5 \mathrm{~A} / \mathrm{div} . \mathrm{i}_{\mathrm{o}}: 0.5 \mathrm{~A} / \mathrm{div} . \mathrm{H}: 100 \mu \mathrm{s} / \mathrm{div}$.

Fig. 13. Load-change experimental results from heavy load to light load (PWM control).

Fig. 12 shows waveforms for $e_{0}, i_{L}$ and $i_{0}$ at the change point from light load to heavy load.

From the results of PWM control, it was confirmed that the response time is $150 \mu \mathrm{s}$, with an undershoot of $80 \mathrm{mV}$. The ripple of the reactor current is $0.95 \mathrm{~A}$ at light load, and $0.97 \mathrm{~A}$ at heavy load. Therefore, the ripple of the reactor current increases by approximately $20 \mathrm{~mA}$. Also, the noise of the output voltage was greater for the heavy load than for the light load. The switching frequency was fixed at $500 \mathrm{kHz}$, and the on-term increases to step up the output voltage in the load change.

Fig. 13 shows waveforms for $e_{o}, i_{L}$ and $i_{o}$ at the change point from heavy load to light load.

From the results of PWM control, it was confirmed that the response time is $200 \mu \mathrm{s}$, with an overshoot of $60 \mathrm{mV}$. The switching frequency was fixed at $500 \mathrm{kHz}$, and the on-term decreases to step down the output voltage in the load change.

\section{B. Proposed PRC}

The experiments were performed using a PRC-IC (SI8405N, Sanken Electric Co., Ltd.) [6].

Fig. 14 shows the experimental circuit, and Table 4 gives the experimental conditions.

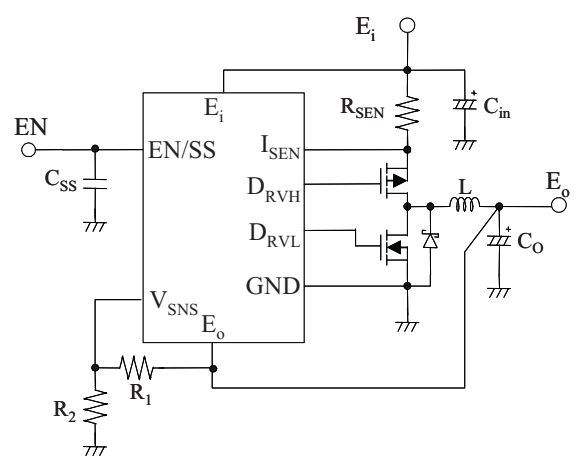

Fig. 14. Experimental circuit (PRC) 
Table IV.

\begin{tabular}{|c|c|c|c|}
\hline Input voltage $\mathrm{E}_{\mathrm{i}}$ & $5 \mathrm{~V}$ & \multirow{2}{*}{$\begin{array}{c}\text { Load current } \mathrm{i}_{\mathrm{o}} \\
\text { (light load-heavy load) }\end{array}$} & \multirow[b]{2}{*}{$0 \mathrm{~A}-1.4 \mathrm{~A}$} \\
\hline Output voltage $\mathrm{E}_{\mathrm{o}}$ & $2.5 \mathrm{~V}$ & & \\
\hline Switching frequency $\mathrm{f}_{\mathrm{s}}$ & $500 \mathrm{kHz}$ & Choke inductor $\mathrm{L}$ & $2.7 \mu \mathrm{F}$ \\
\hline On-term $\mathrm{T}_{\mathrm{ON}}$ & $1 \mu \mathrm{s}$ & Output capacitor $C_{o}$ & $330 \mu \mathrm{F}$ \\
\hline \multirow{2}{*}{$\begin{array}{c}\text { soft-start capacitor } \\
\mathrm{C}_{\mathrm{ss}}\end{array}$} & \multirow{2}{*}{$0.022 \mu \mathrm{F}$} & Input capacitor $\mathrm{C}_{\text {in }}$ & $20 \mu \mathrm{F}$ \\
\hline & & \multicolumn{2}{|c|}{ MOS Pch/Nch 1PkgSOP8(Toshiba) } \\
\hline
\end{tabular}

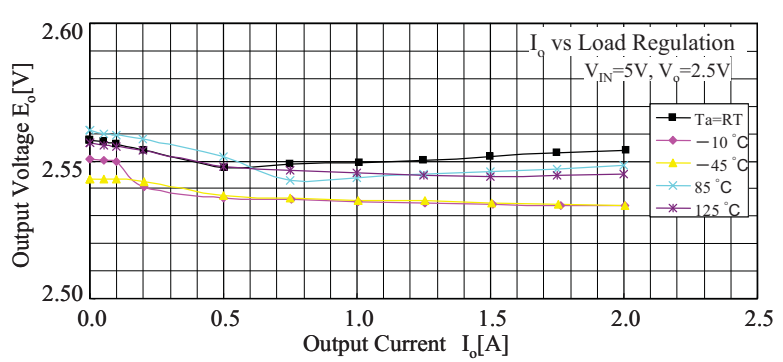

Fig. 15. $\mathrm{I}_{\mathrm{o}}-\mathrm{E}_{\mathrm{o}}$ characteristic.

Fig. 15 shows the $I_{0}-E_{0}$ characteristics for various temperatures.The error is a maximum of $0.02 \mathrm{~V}$ for the temperature change. The error rate with a standard voltage is within $2 \%$. Therefore, it was confirmed that highly accurate control is achieved.

Fig. 16 shows waveforms for $\mathrm{e}_{\mathrm{o}}, \mathrm{i}_{\mathrm{L}}$ and $\mathrm{i}_{\mathrm{o}}$ at the change point from light load to heavy load. From the results of PRC, it was confirmed that the response time is $6 \mu \mathrm{s}$, with an undershoot of $20 \mathrm{mV}$. The ripple of the reactor current is $0.77 \mathrm{~A}$ at light load, and $0.62 \mathrm{~A}$ at heavy load. Therefore, the ripple of the reactor current decreases by approximately $150 \mathrm{~mA}$. The switching frequency is 500,620 and $830 \mathrm{kHz}$ at light load, during transition and at heavy load, respectively. When the load current increases, it was confirmed that the switching frequency also increases.

Fig. 17 shows waveforms for $\mathrm{e}_{\mathrm{o}}, \mathrm{i}_{\mathrm{L}}$ and $\mathrm{v}_{\mathrm{g}}$ at the change point from heavy load to light load. From the results of PRC, it was confirmed that the response time is $4 \mu \mathrm{s}$, with an overshoot of $40 \mathrm{mV}$. The switching waveform is kept as an offterm during transition, until the output voltage falls to the target output voltage.

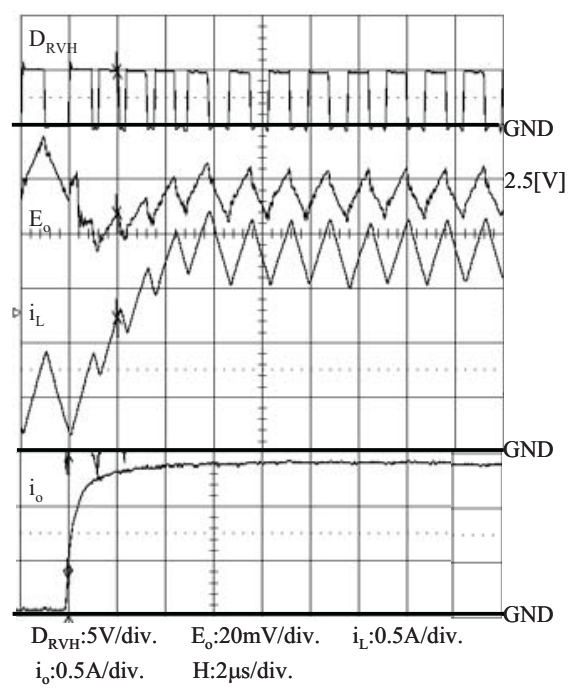

Fig. 16. Load-change experimental results from light load to heavy load (PRC).

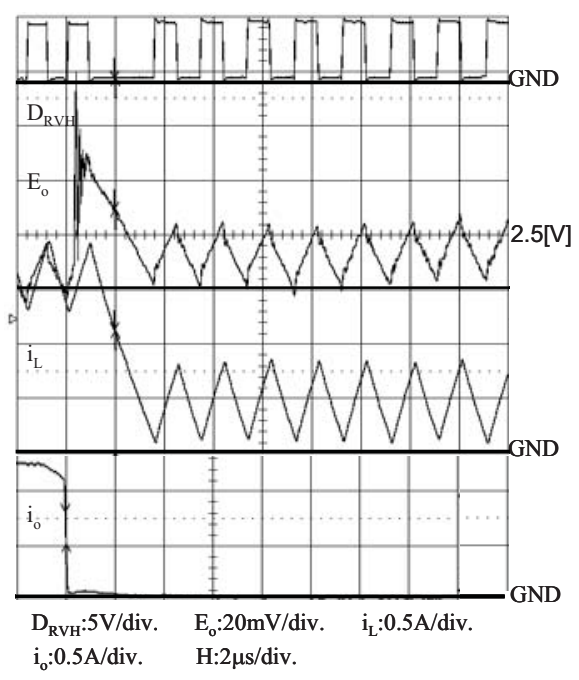

Fig. 17. Load-change experimental results from heavy load to light load (PRC).

\section{CONCLUSION}

PWM and PRC control were compared from the aspect of dynamic characteristics using a simulation and experiments. The results gained from PRC suggest that the response time was decreased dramatically. These results indicate that PRC not only allows fast response but also fast convergence. In addition, $\Delta \mathrm{i}_{\mathrm{L}}$ decreased after the load change. This suggests that the increase in the switching frequency cancelled out the influence of the DC bias. The switching frequency was 500, 620 and $830 \mathrm{kHz}$ at light load, during transition and at heavy load, respectively.

\section{ACKNOWLEDGEMENT}

This work was supported in part by the Grant-in-Aid for Scientific Research (No.16560246) of Japan Society for the Promotion of Science and the Ministry of Education, Science, Sports and Culture.

\section{REFERENCES}

[1]Ed Stanford, Materials Technology Operation Intel Corporation; "Microprocessor Voltage Regulators and Power Supply Trends and Device Requirements" Proceedings of 2004 International Symposium on Power Semiconductor Devices \& Ics, Kitakyusyu, pp.45-50

[2]Kaiwei Yao, "High-Frequency and High-Performance VRM Design for the Next Generations of Processors," Doctor thesis of Virginia Polytechnic Institute and State University, April 14, 2004.

[3] Edward Lam, Robert Bell and Donald Ashley, "Revolutionary Advances in Distributed Power Systems," in Proc. IEEE APEC '03 , 2003, 1.5.

[4] Ming Xu, Julu Sun and Fred C. Lee, "Voltage Divider and its Application in the Two-stage Power Architecture," IEEE APEC'06 , 2006, 15.6_11051.

[5]TEXAS INSTRUMENTS Co.., Data sheet TPS40050, Revised March 2003.

[6] Sanken Electric Co., Ltd., Application Note SI-8405N, Feb., 2006. 